\title{
Formation and retention of conditioned taste aversions and UCS habituation
}

\author{
KENNETH H. BROOKSHIRE and ROBERT M. BRACKBILL \\ Franklin and Marshall College, Lancaster, Pennsylvania 17604
}

\begin{abstract}
In Experiment I rats received 10 consecutive daily injections of either apomorphine hydrochloride or $\mathrm{NaCl}$ followed by 4 days of saccharin solution exposure paired with apomorphine or $\mathrm{NaCl}$ injections. Relative consumption of saccharin solution and water during conditioning indicated that preconditioning apomorphine UCS habituation retarded acquisition of a conditioned saccharin aversion. In Experiment II rats received 6 days of saccharin solution exposure paired with injections of either apomorphine hydrochloride or $\mathrm{NaCl}$, then 10 daily injections of either apomorphine hydrochloride or $\mathrm{NaCl}$, followed by 4 days of saccharin preference testing (no drug injections). Postconditioning apomorphine UCS habituation did not interfere with retention of saccharin aversion acquired in initial conditioning phase. These results showed that novelty of UCS is crucial in acquisition of but not retention of conditioned taste aversions.
\end{abstract}

For classical conditioning in general and conditioned taste aversion learning in particular, habituation to an unconditioned stimulus (UCS) prior to conditioning attenuates degree of conditioning expressed as either retarded acquisition or reduced resistance to extinction. For example, retarded acquisition of a conditioned response following preconditioning UCS habituation was found in human eyelid conditioning (MacDonald, 1946; Taylor, 1956), in rabbit nictitating membrane conditioning (Mis \& Moore, 1973; Siegel \& Domjan, 1971), and in conditioned suppression (Kremer, 1971; Siegel \& Domjan, 1971). Rescorla (1973) reported reduced resistance to extinction and not retarded acquisition of conditioned suppression as a result of preconditioning noise UCS habituation. Regarding conditioned taste aversion learning, both retarded acquisition (Cannon, Berman, Baker, \& Atkinson, 1975; LeBlanc \& Cappell, 1974) and reduced resistance to extinction (Elkins, 1974) have resulted from preconditioning UCS habituation using ethanol, lithium chloride, cyclophosamide, morphine, or amphetamine as drug UCSs. Experiment I investigated acquisition of conditioned taste aversion as a function of preconditioning UCS habituation when an apomorphine hydrochloride UCS was used.

Attenuation of conditioning by UCS habituation is not limited to UCS habituation done prior to conditioning, for UCS habituation administered following conditioning has been found to reduce resistance to extinction of conditioned suppression in rats (Rescorla, 1973). Experiment II is an investigation

This paper was originally presented at the meeting of the Psychonomic Society, St. Louis, Missouri, in 1971 by Kenneth H. Brookshire, who is now deceased. The study was supported by Grants GB-3434 and GY-5906 from the National Science Foundation. Reprint requests should be addressed to Robert M. Brackbill, Department of Psychology, University of Minnesota, Minneapolis, Minnesota 55455. of retention of a conditioned aversion following the same number of apomorphine UCS habituation trials administered in Experiment I.

\section{EXPERIMENT I}

\section{Method}

Subjects. The subjects were 32 male Sprague-Dawley rats 49 days old at the beginning of the experiment, with a mean body weight of $205 \mathrm{~g}$.

Apparatus. Animals were housed in test boxes which had three adjacent holes, $65 \mathrm{~mm}$ apart, and clips for insertion of graduated Richter tubes. The saccharin solution contained $1 \mathrm{~g}$ of sodium saccharin in 1 liter of distilled water $(.1 \%$ sodium saccharin solution). The apomorphine hydrochloride injections consisted of $15 \mathrm{mg}$ of apomorphine hydrochloride per kilogram of body weight in a solution of $5 \mathrm{mg}$ apomorphine hydrochloride per milliliter of $.9 \% \mathrm{NaCl}$ solution; control injections were an equal volume of $.9 \% \mathrm{NaCl}$ solution (saline solution) following the same dose per weight schedule for apomorphine hydrochloride injections.

Procedure. During the first 5 days of the experiment, all subjects were placed on a 23-h water deprivation schedule and received distilled water in a Richter tube placed through the center hole of the test box. For the next 10 days (habituation phase), 16 subjects received daily injections of apomorphine hydrochloride. The remaining 16 subjects received saline control injections. Injections were given $1 / 2 h$ after termination of a drinking period.

For the next 5 days (conditioning phase), each group of 16 subjects was subdivided into two groups of equal size. One of the groups which had received habituation to apomorphine-induced illness (Group pre A-A) and one of the groups which had served as a saline solution control for habituation (Group pre S-A) were given 1-h periods with exposures to $.1 \%$ sodium saccharin and distilled water for 5 successive days. Richter tubes were placed in each lateral position of the test box; solution positions were rotated daily. One-half hour after termination of each drinking period, subjects were injected with apomorphine hydrochloride using the same procedure as that employed in the habituation phase. The other two subgroups (pre A-S and pre S-S) also received the $1-\mathrm{h}$ two-choice drinking procedure but were given a saline control injection $1 / 2 \mathrm{~h}$ after drinking tubes were removed. 


\section{Results}

Amount of distilled water ingested on the last day of the habituation phase was not reliably different between subjects receiving apomorphine injections and those receiving control $\mathrm{NaCl}$ injections $[\mathrm{t}(30)=.049, \mathrm{p}>.5]$. Thus, illness did not affect water consumption during UCS habituation.

Observations of animals during the habituation phase indicated that the illness produced by an apomorphine injection manifested itself within 5 min after injection of the drug. Animals showed extreme agitation, climbed the walls of the cage, bit or licked the bars of the cage, and sometimes showed uncoordinated movements. Behavioral symptoms lasted approximately $90 \mathrm{~min}$ and were just as prevalent after the 10th daily injection as after the first.

The percentage preference score for saccharin solution during each of 5 days of conditioning phase was computed by dividing volume of saccharin by total saccharin and water consumed. Figure 1 shows the mean percentage preference scores of each group for each of 5 conditioning days. For Day 1 it should be noted that there is no difference in preference scores for saccharin solution between apomorphine injected and $\mathrm{NaCl}$ injected animals $[\mathrm{t}(30)=.96, \mathrm{p}>.25]$. This preference score for Day 1 of the conditioning phase is an index of relative preference between water and saccharin $24 \mathrm{~h}$ following the last habituation trial and before the first conditioning trial presentation of UCS. For the last 4 days of the conditioning phase, it was readily apparent that subjects receiving $\mathrm{NaCl}$ injections during the habituation phase but apomorphine injections during the conditioning phase (Group pre S-A) formed a conditioned aversion to saccharin. However, subjects which had received 10 habituation trials prior to conditioning (Group pre A-A) showed a preference for saccharin which was quite similar to the groups for which saccharin was never paired with illness (Groups pre A-S and pre S-S). Analysis of variance (habituation treatment by conditioning treatment by trials) supported this: Conditioning treatment had a significant effect $[F(1,28)=18.2, p<.01]$ and the interaction of Habituation Treatment by Conditioning Treatment was significant $[\mathrm{F}(1,28)=18.8, \mathrm{p}<.01]$. Scheffe tests yielded a significant difference between Group pre S-A and other groups but no reliable differences among the other groups.

\section{EXPERIMENT II}

\section{Method}

Subjects. The subjects in this experiment were 32 male Sprague-Dawley rats, 51 days old at the beginning of the study, with a mean body weight of $209 \mathrm{~g}$.

Apparatus. Same as in Experiment I.

Procedure. As in Experiment I, the subjects were placed on a 23-h water deprivation schedule for 5 days. Then for 6 successive days all subjects received a 1-h exposure to Richter tubes containing either saccharin solution or water.

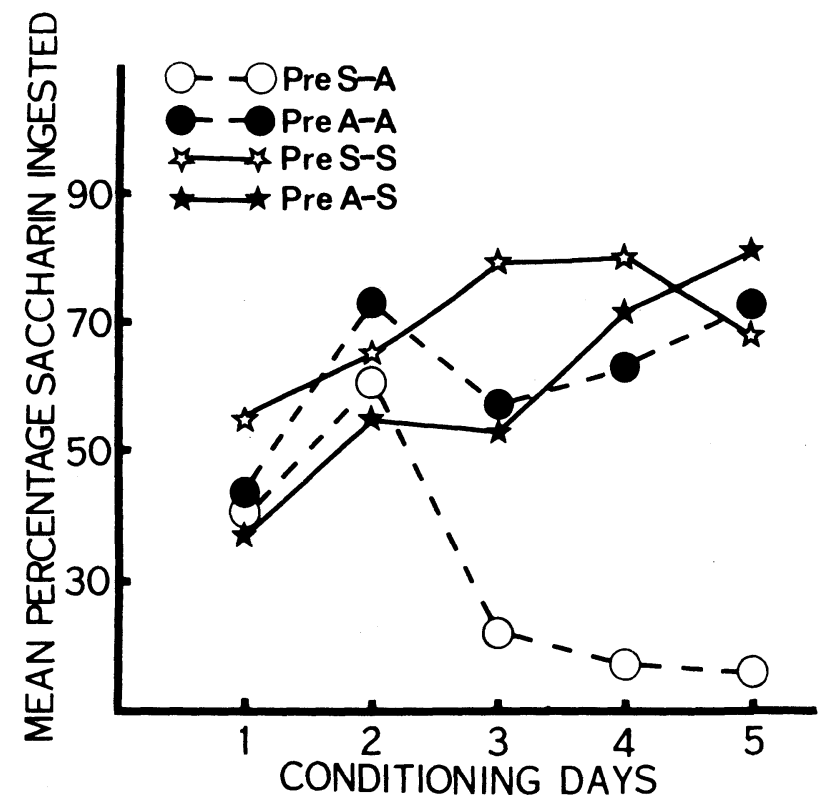

Figure 1. Mean percentage preference for saccharin over Conditioning Days 1-5 for the groups of Experiment $I$. Groups pre A-A and pre A-S received UCS habituation trials prior to conditioning; Groups pre S-A and pre S-S were injected with saline prior to conditioning.

One-half hour after termination of the drinking period, 16 subjects received an injection of apomorphine hydrochloride and 16 subjects received a saline control injection (conditioning phase).

Following the conditioning phase, all subjects were returned to $1 \mathrm{~h}$ daily exposure to water only. Eight subjects from each previous group of 16 (Groups A-post A and S-post A) received 10 daily injections of apomorphine $1 / 2 \mathrm{~h}$ after termination of the drinking period. The remaining animals (Groups A-post $S$ and S-post S) received saline control injections.

Finally, all subjects received a 3-day 1-h two-tube choice test between saccharin solution and water to determine whether habituation trials with the illness-producing UCS after taste aversion conditioning would affect the acceptability of the saccharin conditioned stimulus for experimental subjects (test phase).

\section{Results}

The saccharin preference scores over the 6 conditioning days of the conditioning phase of the experiment for the subjects receiving pairings of saccharin and apomorphine injections, that is, Groups Apost $A$ and A-post $S$ combined, and the subjects receiving pairings of saccharin and control injections, that is, Groups S-post A and S-post S combined, are in the first part of Figure 2. Analysis of variance (conditioning treatment by trials) indicated that subjects receiving saccharin-apomorphine pairings showed a reliable diminution of preference for saccharin $[F(1,30)$ $=9.22, \mathrm{p}<.01]$, although the subjects in Experiment II did not avoid saccharin to the extent that subjects in Experiment I did.

The second part of Figure 2 shows the preference scores for each experimental group during the test 


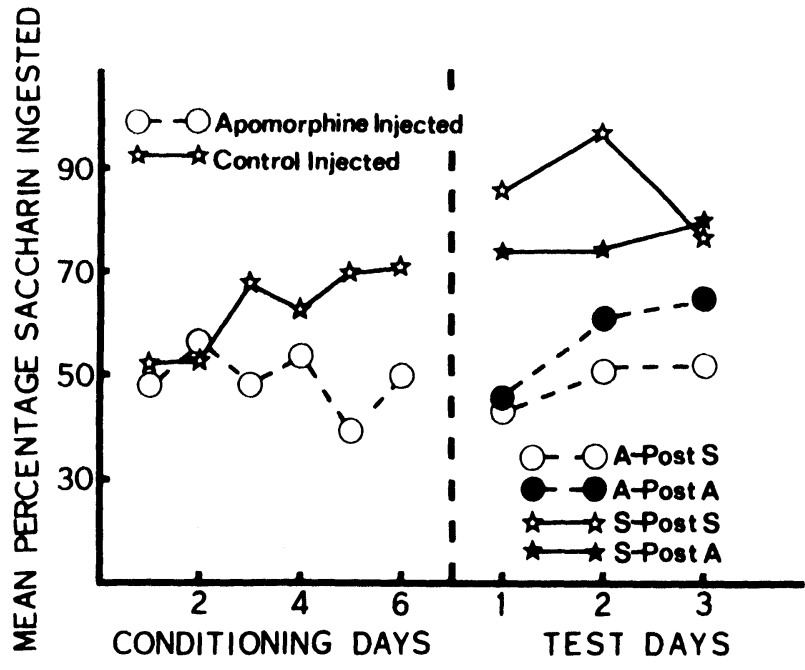

Figure 2. Mean percentage preference for saccharin over Conditioning Days 1-6 and Test Days 1-3 for the groups of Experiment II. Groups A-post A and S-post A received UCS habituation trials following conditioning; Groups A-post $S$ and S-post $S$ were injected with saline following conditioning.

phase. An analysis of variance (conditioning treatment by habituation treatment by trials) done on test phase saccharin preference scores showed that postconditioning UCS habituation did not affect retention of aversion for the A-post A group. The conditioning treatment factor was significant $[F(1,28)=29.12, p<.01]$, while the habituation factor was not significant as a main factor $[F(1,28)<1]$ or in its interaction with the conditioning treatment factor $[F(1,28)=2.27$, $\mathrm{p}>.11$.

\section{GENERAL DISCUSSION}

The results of Experiment $I$ indicate that, when subjects received 10 daily UCS habituation trials prior to conditioning, a saccharin taste aversion was not learned. This data parallels attenuation of conditioned response (CR) acquisition following conditioned stimulus (CS) pre-exposure for both conditioned taste aversion (Ilkins, 1973) and classical conditioning (Lubow, 1973). More specifically, it parallels retarded acquisition of a C.R following UCS habituation trials in a number of classical conditioning settings, e.g.; Siegel and Domjan (1971), in addition to reduced resistance to extinction of a conditioned taste aversion following illness UCS habituation (Cannon et al., 1975; Flkins, 1974; LeBlanc \& Cappel, 1974).

In lixperiment II, the postconditioning UCS habituation group (A-post A) clearly retained saccharin aversion acquired in the conditioning phase. Moreover, there is no indication of reduced resistance to extinction for this group relative to Group A-post S. This is counter to the diminution of conditioned suppression over extinction test days following UCS habituation reported by Rescorla (1973).

Several explanations are available to account for the effect of UCS habituation in Experiment I. Because the UCS in this study was presented by injection of a drug, specifically, a narcotic, there is danger that multiple injections could have produced drug resistance. Several arguments reduce the likelihood of drug tolerance playing a primary role in lixperiment $I$. First, Sollman (1943) reported that repeated administration of apomorphine hydrochloride for 42 days did not produce drug tolerance in dogs, a test far more severe than the 10-day drug exposure used in this experiment. Second, observation of rats during the illness period following apomorphine injection in lixperiment $I$ indicated that apomorphine-induced illness continued to occur fully, at least reflected by several indexes used to assess degree of illness.

A second possible account would be based on a parallel to a blocking phenomenon (Kamin, 1969), in which a number of CS-UCS pairings with one (SS will "block" conditioning to a second CS presented in compound with the previously paired (SS. Relevant to Iixperiment I, the situational cues and the water drinking were inadvertently paired with the UCS during the habituation phase. However, it should be noted that (1) amount of water ingested by habituated animals was not different from that ingested by control $\mathrm{NaCl}$ animals during the last day of the habituation phase, and (2) pereentage of water drunk in two-tube choice with saccharin on Conditioning Phase Day 1 of lixperiment I was no different between UCS habituated groups and control groups; these two observations reduce the likelihood of a blocking aversion to water having been formed during the habituation phase.

Nonlearning of a saccharin aversion by animals habituated to UCS in Experiment I could have resulted from a change in the nature of the UC.S per se. Just as novelty of taste CS is important in establishing a conditioned taste aversion (Revusky \& Bedarf, 1967), novelty of UCS may in a complementary fashion also be important. Alternatively, a recent theoretical account postulated by Rescorla (in press) maintains that an alteration of memory of UCS, e.g., UCS habituation, will reduce the degrec of associative power supported by a CS in relation to a particular UCS. This model has been used to account for reduced bchavioral control of a CS following postconditioning habituation to UCS (Rescorla, 1973). The novelty hypothesis is sufficient to account for both Experiments I and II, while, on the other hand, the memory hypothesis is not supported by the results of Experiment II.

\section{REFERENCES}

Cannon, D. S., Berman, R. F., Baker, T. B., \& Atkinson, C. A. Effect of preconditioning unconditioned stimulus experience on learned taste aversions. Journal of Experimental Psychology: Animal Behavior Processes, 1975, 104, 270-284.

Elkins, R. L. Bait-shyness acquisition and resistance to extinction as a function of US exposure prior to conditioning. Physiological Psychology. 1974, 2, 341-345.

Elkins, R. L. An attenuation of drug-induced bait shyness to a palatable solution as an increasing function of its availability prior to conditioning. Behavioral Biology. 1973, 9, 221-226

Kamin, L. J. Predictability, surprise, attention, and conditioning. In B. A. Campbell and R. M. Church (Eds.), Punishment and aversive behavior. New York: Appleton-Century-Crofts. 1969. Pp. 279.296.

Kremer, E. F. Truly random and traditional control procedures in CER conditioning in the rat. Journal of Comparative and Physiological Psychology, 1971, 76, 441-448.

LeBlanc, A. E., \& Cappell, H. Attenuation of punishing effects of morphine and amphetamine by chronic prior treatment. Journal of Comparative and Physiological Psychology, 1974, 87, 691-698.

Lubow, R. E. Latent inhibition. Psychological Bulletin, 1973, 79, 398-407.

MacDonal.D, $A$. The effect of adaptation to the unconditioning stimulus upon the formation of conditioned avoidance responses. Journal of Experimental Psychology, 1946, 36. 1-12. 


\section{BROOKSHIRE AND BRACKBILL}

Mis, R. W.. \& Moore, J. W. Effects of preacquisition UCS exposure on classical conditioning of the rabbit's nictitating membrane response. Learning and Motivation, 1973. 4. 108-114.

RESCORLA. R. A. Effect of US habituation following conditioning. Journal of Comparative and Physiological Psychology, 1973, 82. 137-143.

Rescorla, F. A. A model of Pavlovian conditioning. In V. S. Rusinov (Ed.), Mechanisms of formation and inhibition of conditioned reflex. Moscow: Nauka Academy of Science of the USSR, in press.
ReVusky, S. H., \& Bedarf, E. W. Association of illness with prior ingestion of novel foods. Science, 1967, 155, 219-220. Siegel, S., \& Domuan, M. Backward conditioning as an inhibitory procedure. Learning and Motivation, 1971, 2, 1-11.

Stollman, T. A manual of pharmacology. Philadelphia: Saunders, 1943.

TAYLOR. J. Level of conditioning and intensity of the adaptation stimulus. Journal of Experimental Psychology, 1956, 51. $127-130$.

(Received for publication November 3, 1975.) 